Journal of Computer Science 2 (4) : 314-317, 2006

ISSN 1549-3636

(C) 2006 Science Publications

\title{
Evaluating Web Usability from the User's Perspective
}

\author{
${ }^{1}$ Hema Banati, ${ }^{1}$ Punam Bedi and ${ }^{2}$ P.S.Grover \\ ${ }^{1}$ Department of Computer Science University of Delhi, India \\ ${ }^{2}$ IBS, Gurgaon, India
}

\begin{abstract}
The presence of multiple websites offering similar services has changed the user outlook. The user now prefers to visit those sites, which are easy to use. Many different methods have been proposed to measure usability of a website. The quantitative methods focus on the performance measurement of the website whereas the qualitative methods estimate the user's opinion of a website. However none of these specify measurement of the human emotions; the emotional experiences of the user during the website visit. This emotional aspect plays a strong guiding force in the way a user uses the website. In this paper we propose a distinct measure, which combines the qualitative, quantitative factors referred in the literature with rarely mentioned factors such as trust and feature state. The measure thus obtained determines the usability of a website from the user view point .It can be employed to compare usability of different websites.
\end{abstract}

Keywords: Web usability, trust, usability measure

\section{INTRODUCTION}

The invasion of Internet in our day-to-day lives has increased the significance of web usability. With many websites offering similar facilities, the user today has become more demanding in respect of the web access. Users prefer visiting those sites, which are easy to learn and operate and are aesthetically appealing. The usability of a website plays a significant role in determining the number of hits to a website.

Usability in ISO/IEC 9126-1 ${ }^{[1]}$ is defined as "The capability of the software product to be understood, learned, used and attractive to the user, when used under specified conditions". Many organizations have now started incorporating usability lifecycle in their software development life cycle. Various usability maturity models have been proposed ${ }^{[2,3]}$. All these models help in comparing the usability levels attained by different organizations. However these do not provide an insight into the users' perspective regarding the usability of a website. The human aspect needs to be stressed as user plays a central role in usability.

Our paper proposes a four-tier approach to improve usability from the user viewpoint. Each of these tiers consider the human dimension of the user's attitude towards the website.

Usability measurement methods: There are two main types of methods to evaluate usability of a website. These are the inspection methods and the user test methods. The inspection methods such as the Heuristic evaluation $^{[4,5]}$, cognitive walkthrough ${ }^{[6]}$, Pluralistic usability walk-through ${ }^{[7]}$ and collaborative usability inspection $^{[8]}$ help in detecting the usability problems.
The developers or usability experts frequently employ these methods. The role of the end user is limited in inspection techniques.

Usability testing or the user test methods employ techniques to collect data while representative users use the product to perform representative tasks. These can be either formal in nature, where actual experiments are conducted to accept/reject a hypothesis or an iterative cycle of test can be conducted to identify the usability deficiencies and gradually improve the concerned product $^{[9]}$. Test Methods such as thinking aloud ${ }^{[4]}$, Field Observation $^{[10]}$, Questionnaires ${ }^{[1]]}$, interviews and focus groups $^{[4,12]}$ etc are extensively used to gauge the satisfaction, user opinion about features of the product. Both the methods have their own advantages and disadvantages. An effective usability process should ideally combine the inspection and user testing methods $^{[13-15]}$.

However, all these approaches assess usability independently. Separate measures do not provide a complete view of the usability of the website. A single measure is required which can tell the level of usability level of a website. Some study has been directed towards this aspect also. Babiker et al. ${ }^{[1]}$ found a single metric for usability of hypertext systems. They derived this measure by the objective performance measures but correlated it to subjective assessment measures. Corde ${ }^{[17]}$ and Mc Gee ${ }^{[18,19]}$ used magnitude estimation to estimate usability. All these studies take a very experimental assessment of usability. Since usability is a phenomenon closely related to the user behavior and attitude towards a website, hence it is imperative that the users' perceptions should be considered while measuring usability. In this paper we propose a measure

Corresponding Author : Hema Banati, Department of Computer Science University of Delhi, India 
to assess usability as viewed by user during the different stages.

Our approach: Here, we identify the various factors and criteria that influence usability. While the factors influence usability externally, the criteria measure the different aspects associated with usability.

Factors influencing web usability: The various factors which can influence the usability of a website are explained as follows:

Stakeholders-of the website: A stakeholder is an individual or an organization who is affected by the performance of the website. There are three main categories of the stakeholders, "the actual users", " the designers" and " the organization hosting the website" ${ }^{,[20]}$. All these perceive usability of a website in a different light.

User profile : The age and the cultural upbringing of the user influences the way a user uses a website.

User experience : The experience of user includes different parameters such as the computer knowledge, the amount and the frequency of usage of Internet by the user and the kind of work the user uses the Internet for. On the basis of experience the users can primarily be classified into novice, expert and professional users.

Type of website : Websites can primarily be classified into 3 main categories, the information-oriented websites, the service-rendering websites and the business-oriented websites ${ }^{[21]}$. This classification is based on the prime purpose the website is intended for. Usability measurement criteria

Different scientists have proposed different criteria to measure usability. Shackel ${ }^{[22]}$ identified speed effectiveness, error effectiveness, both in learnability flexibility and attitude as the major criteria affecting usability. Nielsen's ${ }^{[4]}$ five criteria of usability: learnability, efficiency of use, memorability, errors and satisfaction are often quoted. Hix and Hartson ${ }^{[23]}$ related learnability, long term performance, retainability and long term user satisfaction to usability. Preece et al. ${ }^{[24]}$ described usability in terms of throughput, learnability and attitude. Wixon and Wilson ${ }^{[25]}$ characterized usability by learnability, efficiency, memorability, error rates and satisfaction. Shneidermann ${ }^{[26]}$ cited usability criteria as time to learn, speed of performance, retention over time, rate of errors by users and subjective satisfaction. Constantine and Lockwood ${ }^{[27]}$ defined usability in terms of efficiency in use, learnability, rememberability, reliability in use and user satisfaction. We here cite the most often identified the criteria in the literature.
These are:

* Efficiency

* Effectiveness

* Learnability,

* Memorability

* Appearance of the site

* Satisfaction

Since usability is primarily a user oriented concept, therefore we include criteria pertaining to concepts which can gauge the user's experience with the website. To have a more humane oriented aspect we extend the term satisfaction to include the term work satisfaction and emotional satisfaction. The term work satisfaction implies that the user is able to satisfactorily achieve the task which he/ she wanted to perform. During our study we observed that not many users were satisfied with the way the task was performed even after successfully completing the task. The criteria work satisfaction would measure this aspect of user attitude. The term emotional satisfaction includes the pleasure / frustration which the user experience while performing the task. The users experience various lows/ highs while executing the tasks. These can be linked to the site structure, content organization, navigational ease etc.

Another prime criteria associated with the usability of a site is the trust the user places on a site. The relationship between usability and trust is a very complex relationship. Different schools of thought project the relationship between trust and usability in a different manner. Scientists like Egger ${ }^{[28]}$ are of the opinion that usability is a component affecting trust whereas Fogg ${ }^{[29]}$ suggests that trust and usability both are components of credibility.

The relationship between the two is analogous to the chick-egg relationship. It is debatable whether a usable site leads to trust formation or trust increases the usability of a website just like the chick or egg situation.

We propose that both are closely related to each other. Initial reputation (a trust parameter) of a site might lead to the first visit to the site. If the user finds the site usable, then there might be revisits. This increases the duration of relationship between the user and the website, which enhances the user trust on the website.

On the other hand a first time browsing of the site may encourage the user to revisit the site, if it is usable. A satisfied user spreads reputation of the site's leading to increase trust in the website. Figure 1 depicts the inter-relation between usability and trust.

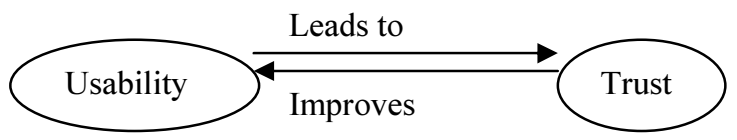

Fig. 1: Relation between trust and usability 
The state of a feature also influences the degree of usability of a website. A feature can be in one of the four possible states "Irritant", "Chaotic", "Assuring" and "Motivating",[30]. These states are determined by the design of the website and hence affect the usability of the website.

We propose the following extended list of criteria to measure usability

* Efficiency

* Effectiveness

* Learnability,

* Memorability

* Appearance of the site

* Work satisfaction

* Emotional satisfaction

* State of features

* Trustworthiness of the site

Usability pyramid: Our aim is to obtain a complete measure of usability. However, usability cannot be achieved in a single step. It needs repeated iterations to evolve a usable website. Figure 2 presents the usability pyramid. Each of these stages should be completed before moving on to the higher stage. A site, which does not satisfy the conditions of the $\mathrm{I}^{\text {st }}$ stage, is not considered usable.

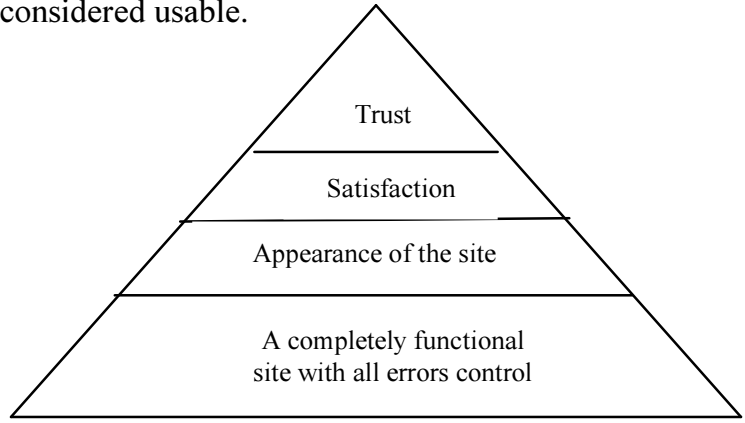

Fig. 2: Usability pyramid

The pyramid is built keeping in mind the key requirements of usable website. A site in order to be considered for usability should be completely functional with all links working, correct information and complete prevention and recovery of errors. Only when a site possesses this then the attention should be diverted to the aesthetic appearance of the site. The look and feel of the site along with the ease of navigation contribute to improving the usability of the site to the next level. Along with this proper attention is to be paid to the ease of learning to use and memorizing the workflow of the site. These all lead to a degree of work satisfaction. The focus of the next stage should therefore be to provide the user with an emotional satisfaction. The ultimate stage however is to encourage the user to have complete faith in the website.

Determination of usability measure : We now propose a formula for determining usability quantitatively by considering all aspects influencing usability. Figure 3 presents the complete scenario of usability measurement. The circles represent the external factors influencing the usability of the site whereas the criteria affecting each stage of the pyramid are in rectangular boxes.

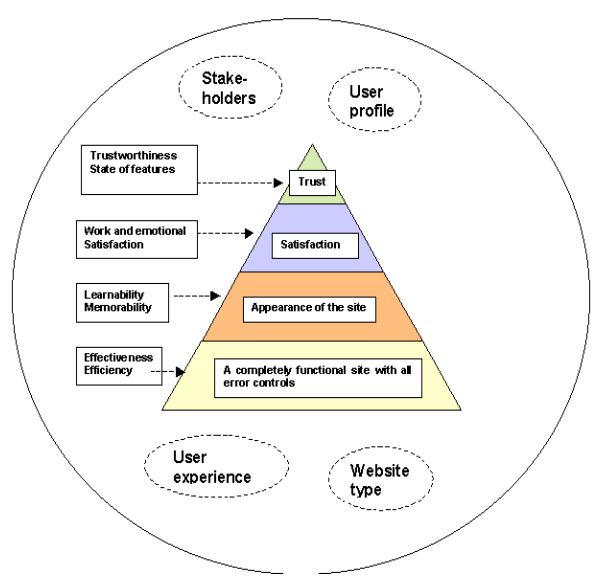

Fig. 3: The complete usability picture

Usability measure $=\mathrm{s} 1+2 * \mathrm{~s} 2+3 * \mathrm{~s} 3+4 * \mathrm{~s} 4$

Where si refers to the criteria affecting the ith stage.

$\mathrm{s} 1=0.5 *$ effectiveness value measured $+0.5 *$ efficiency value measured.

s2 $=0.33 *$ Learnability value measured $+0.33 *$ memorability value measured $+0.33 *$ rating of appeal

$\mathrm{s} 3=0.5 *$ emotional satisfaction $+0.5 *$ work satisfaction $\mathrm{s} 4=\quad$ measured trust value

The metrics in ISO-9126 $6^{[1]}$ can be employed to measure the parameters such as effectiveness, efficiency, Learnability and appeal of the website. For measuring the human attitude such as the trust and satisfaction of the user, Intuitionsitic Fuzzy Sets $(I F S)^{[20]}$ can be used. IFS are most suited to capture the uncertainty of human thought process.

The result obtained is a numerical quantity, which considers all the qualitative aspects of usability.

A consensus view of usability measures obtained by each user can be obtained ${ }^{[4]}$. The consensual opinion of all users considering the various factors will provide the complete measure of usability.

The weights are assigned in order of the significance of each of the parameters. The lower stages of the usability are easy to design and maintain which a trained web designer can do. The role of the HCI expert increases at the higher end where it is imperative to understand the user's needs and attitude and incorporate those requirements in the apparently usable website. The top of the pyramid is the most difficult to manage as building trust is difficult, losing is easier. The HCI expert needs to identify the crucial factors which build the emotional bonding of the user with the website forming a complete trustworthy usable website.

\section{RESULTS AND CONCLUSION}

A distinct method of measuring usability based on user perspective is proposed. The inclusion of measures of factors such as trust and satisfaction ensure that the human emotions are represented in usability 
measurement. This is necessary as these guide the outlook of a user towards a website and hence its usage. Assigning weights to these factors ensure that the parameters are measured as per their significance.

A complete measure of usability is obtained. This measure is based on the existing quantitative, qualitative aspects and the emotional aspect of usability. The measure consolidates the different views of usability, the performance oriented, by measuring the effectiveness and efficiency and the user-oriented view by considering the trust and satisfaction levels associated with the usability of website. A measure of usability thus obtained can act as a yardstick for evolving and comparing the usability of different websites.

\section{REFERENCES}

1. ISO 9126-1 Software engineering-Product qualityPart 1: Quality Model, 2000.

2. Jokela,T., 2000. Usability capability modelsReview and analysis. Proc. HCI 2000 Conf., Sunderland,U.K.

3. Jokela,T. And T. Lalli, 2003.Usability and CMMI: Does a higher maturity level in product development mean better usability? CHI, Florida,USA

4. Nielsen, J., 1993.Usability Engineering. Boston: Academic Press.

5. Nielsen, J. and R.L. Mack (Eds.), 1994. Usability Inspection Methods. New York: Wiley.

6. Wharton, C., Rieman, J., Lewis, C. and Polson, P., 1994, "The Cognitive Walk-through Method: A Practitioner's Guide." In Nielsen, J. and Mack, R. L., eds, Usability Inspection Methods, New York: Wiley.

7. Bias, R.G., 1994. The pluralistic usability walkthrough: Coordinated empathies. In Nielsen, J. and Mack, R.L., (Eds.), Usability Inspection Methods, New York: Wiley.

8. Constantine, L.L., 1994a. Collaborative usability inspections for software. Software Development'94 Proc. San Francisco: Miller Freeman.

9. Rubin, J., 1994. Handbook of Usability Testing: How to Plan, Design and Conduct Effective Tests. John Wiley and Sons, Inc.

10. Hackos, J.T. and J.C. Redish, 1998. User and task analysis for interface design. New York, NY: John Wiley and Sons.

11. Foddy, W., 1994. Constructing questions for interviews and questionnaires: Theory and practice in social research. Cambridge, England: Cambridge University Press.

12. Greenbaum, T.L., 1997. The handbook for focus group research. Thousand Oaks, CA: Sage Publications..

13. Kantner, L. and S. Rosenbaum, 1997. Usability studies of WWW Sites: Heuristic evaluation vs. laboratory testing. Proc. SIGDOC'97, Salt Lake City, UT.

14. Nielsen, J. and V.L. Phillips, 1993. Estimating the relative usability of two interfaces: Heuristic, formal and empirical methods compared. Proc. ACM INTERCHI'93 Conf.
15. Rosenbaum, S., 2000. Not just a hammer: When and how to employ multiple methods in usability programs. UPA 2000 Proceedings.

16. Babiker, E.M., H.B. Fujihara and C.B. Craig, 1991. A metric for hypertext usability. In Proc. 11th Annu. Intl. Conf. on Systems Documentation, pp : 95-104. ACM Press.

17. Corde, R.E., 1984. Application of Magnitude Estimation for Evaluating Software Ease of Use. In Gavriel Salvendy (Ed.) First USA-Japan Conference on Human Computer Interaction, Amsterdam, Elsevier Science Publishers.

18. McGee, M.,2003. Usability magnitude estimation. Proc. HFES, 47th Annual Meeting, pp: 691-695.

19. McGee, M., 2004. Master usability scaling: magnitude estimation nd master scaling applied to usability measurement. In Proc. CHI, pp : 3353420 Washington, D.C., ACM Press.

20. Bedi, P. and H. Banati, 2005. Prioritizing web usability attributes using intuitionistic fuzzy sets. Proc. of SERP'05 Software Engineering Research Practices, U.S.A.

21. Banati, H.and P.S. Grover, 2004. A Structured Approach To Study Usability. Natl. Conf. on Software Engineering Principles and Practices.

22. Shackel, B., 1991. Usability-Context, Framework, Design and Evaluation. In Shackel, B., Richardson, $\mathrm{S}$ (eds.). Human Factors for Informatics Usability. Cambridge University Press, Cambridge.

23. Hix, D. and H.R. Hartson, 1993. Developing User Interfaces: Ensuring Usability Through Product and Process. John Wiley and Sons.

24. Preece, J., Y. Rogers, H. Sharp, D. Benyon, S. Holland and T. Carey, 1994. Human Computer Interaction. Addison Wesley.

25. Wixon, D. and C. Wilson, 1997. The Usability Engineering Framework for Product Design and Evaluation. In Handbook of Human-Computer Interaction. Helander, M.G. et al., Elsevier NorthHolland.

26. Shneiderman, B., 1998. Designing the User Interface: Strategies for Effective HumanComputer Interaction. Addison-Wesley.

27. Constantine, L.L. and L.A.D. Lockwood, 1999. Software for Use: A Practical Guide to the Models and Methods of Usage-Centred Design. AddisonWesley, New York.

28. Egger, F. and B. deGroot, 2000. Developing a model of trust for electronic commerce. an application to a permissive marketing web site. In Proc. of the 9th Intl. World-Wide Web Conf., Foretec Seminars.

29. Fogg, B.J., J. Marshall, O. Laraki, A. Osipovich, C. Varma, N. Fang, J. Paul, A. Rangnekar, J. Shon, P. Swani and M. Treinen, 2001. What Makes Web sites Credible? A Report on a Large Quantitative Study, SIGCHI, Seattle, WA,USA.

30. Banati, H. and P. Bedi, 2005. HISE-An algorithmic approach to evolve a usable website. Proc. of HCI'05-Human Computer Interaction, U.S.A. 